\title{
SEnsES: Uma Ferramenta de Suporte a Personalização do Ensino de Engenharia de Software
}

\author{
Andressa B. Ferreira ${ }^{1}$, Rennan R. I. Teles ${ }^{1}$, Bárbara J. F. S. da Silva ${ }^{1}$, David K. \\ A. da Silva ${ }^{1}$, Monick H. N. Macena ${ }^{1}$, Pedro H. A. Dias ${ }^{1}$, João B. C. N. Júnior ${ }^{1}$ \\ ${ }^{1}$ Instituto Federal de Educação, Ciência e Tecnologia do Ceará (IFCE) \\ Caixa Postal 63115-500 - Crato - CE - Brasil \\ \{andressa.ferreira, rennan.teles, bárbara.silva, david.silva, \\ monick.macena, pedro.dias, joão.junior\}@ifce.edu.br
}

\begin{abstract}
Over the years, personalization of teaching has shown a strong tendency in teaching and learning processes. In the area of Software Engineering (SE), it is increasingly common to find student-centered approaches to teaching (e.g. practical projects, games and simulators). Through this scenario, this paper aims to present a software tool capable of personalizing SE teaching. The tool uses as basis for its algorithm Team Role Self-Perception Inventory (TRSPI), method proposed in the area of occupational psychology. As a form of evaluation, the proposed tool was analyzed by teachers of the area and obtained positive results.
\end{abstract}

Resumo. Com o passar dos anos, a personalização do ensino tem se mostrado uma forte tendência nos processos de ensino e aprendizagem. Na área de Engenharia de Software (ES), é cada vez mais comum encontrar abordagens de ensino centradas no aluno (e.g. projetos práticos, jogos e simuladores). Mediante esse cenário, este trabalho tem como objetivo apresentar uma ferramenta de software capaz de personalizar o ensino de ES. A ferramenta utiliza como base para o seu algoritmo o Team Role Self-Perception Inventory (TRSPI), método proposto na área de psicologia ocupacional. Como forma de avaliação, a ferramenta proposta foi analisada por docentes da área e obteve resultados positivos.

\section{Contextualização}

Com o passar dos anos, fica cada vez mais evidente que o ensino é um ato socialmente localizado. Segundo [1], o professor não ensina em situações hipoteticamente semelhantes, mas sim com alunos reais e em situações definidas.

Mediante esse cenário, a personalização do ensino, ou ensino personalizado, tem se mostrado uma forte tendência. Segundo [2], o termo se refere a um conjunto de práticas e estratégias que buscam trabalhar com os estudantes de maneira individualizada, respeitando as habilidades e limitações de cada um ao longo do processo de ensino e aprendizagem.

Atualmente, muito se tem discutido a respeito do ensino e aprendizagem na área Engenharia de Software (ES) [3,4,5]. De acordo com [3], existe um consenso entre 
pesquisadores que abordagens práticas são as mais indicadas para o ensino de ES. Por isso, é bastante comum que sejam realizados projetos práticos de desenvolvimento de software com estudantes dessa disciplina.

Diante desse cenário, este trabalho tem como objetivo apresentar uma ferramenta chamada SEnsES (Sistema para suporte ao ENSino de Engenharia de Software), capaz de diagnosticar conhecimentos prévios e localizar eventuais lacunas e habilidades de estudantes com relação ao desenvolvimento de projetos acadêmicos de software.

A ferramenta, por sua vez, tem como objetivo proporcionar ao professor, subsídios capazes de fazê-lo melhor entender o perfil de cada estudante e, trabalhar com cada um deles, competências complementares às suas habilidades. Para isso, o SEnSES faz uso do Team Role Self-Perception Inventory (TRSPI), proposto na área de psicologia ocupacional.

O TRSPI é um questionário de auto percepção que, segundo [6], serve para classificar indivíduos identificando como eles podem se comportar e melhor contribuir para o sucesso de uma equipe. Segundo [6], dentro de um contexto de trabalho em equipe, todo indivíduo pode ser classificado de acordo com os seus conhecimentos e a sua função técnica. Para tanto, o autor construiu um conjunto de oito papéis (Implementador, Coordenador, Realizador, Criativo, Investigador, Avaliador, Flexível e Finalizador), que descrevem padrões que caracterizam o comportamento de um indivíduo em relação aos outros na facilitação do progresso de um time. O intuito do TRSPI é captar e mostrar a tendência do respondente em se comportar de acordo com as características do perfil.

No trabalho [7], o autor propõe um método capaz de mapear cada um dos papéis do TRSPI para aqueles necessários em uma equipe acadêmica de desenvolvimento de software. Com isso, o autor indica ser possível fornecer subsídios para a personalização do ensino em salas de aula de ES.

No entanto, uma considerável desvantagem do método em [7] é que, para a sua aplicação, o professor necessita ter em mãos uma cópia do TRSPI para cada aluno. Diante disso, os autores apresentam como sugestão de novos trabalhos, a construção de uma ferramenta de software capaz de automatizar a aplicação do método. A partir dessa sugestão, identificou-se a oportunidade de realização desta pesquisa.

\section{A Ferramenta}

A ferramenta SEnsES possui como base algorítmica o mapeamento entre os papéis definidos no TRSPI e aqueles necessários a uma equipe de desenvolvimento de software, proposto e apresentado em [7].

Conforme mencionado na Seção 1, o principal objetivo da ferramenta SEnsES é servir como ambiente para a realização de teste capaz de identificar características e conhecimentos prévios de estudantes de ES. Segundo [7], os resultados do teste podem ser utilizados por professores para personalizar o ensino da disciplina por meio da aplicação de projetos práticos de desenvolvimento de software. 
Ao considerar esse cenário, é possível perceber que docentes e discentes podem ser beneficiados pelo uso da ferramenta. Desse modo, as subseções a seguir são divididas de modo a apresentar, primeiramente, as funcionalidade do SEnsES disponíveis para professores e, a seguir, as funcionalidades disponíveis para os alunos.

\subsection{O SEnsES para Professores}

Para fazer uso das funcionalidades do sistema, basta que o docente, utilizando um computador conectado à internet, acesse a página http://sensesoft.herokuapp.com/.

\section{Uma vez na}

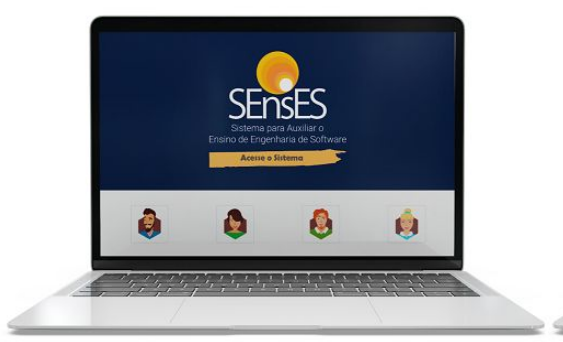

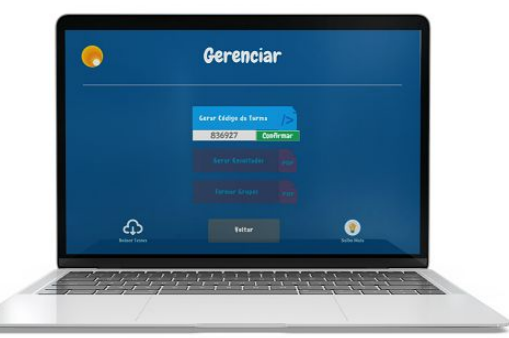

Figura 1: Senses para Professores página, o docente será convidado a realizar seu cadastro. Após cadastrado, será possível logar no sistema e: 1) Acessar o menu Gerenciar Sistema,

onde poderá configurar o início e término da aplicação do teste 2) Acessar o menu Saiba Mais e conhecer um conjunto de informações sobre o sistema 3) Gerar Relatórios com informações sobre os resultados dos testes realizados pelos estudantes.

Há dois tipos distintos de relatórios a serem gerados. O primeiro, disponível por meio do botão Gerar Resultados, apresenta ao professor os resultados individuais de cada estudante. Nesse relatório há nome, matrícula, taxa de acerto, taxa de erro, gabarito e, indicações de qual o papel de equipe de projeto mais adequado às competências e habilidades do estudante.

O segundo, por sua vez, disponível por meio do botão Formar Equipes, apresenta ao professor sugestões de equipes de projeto. Nesse relatório há os nomes dos integrantes de cada equipe e qual o papel de cada um. Para cada equipe, a ferramenta considera necessário 5 papéis: 1 gerente, 1 analista, 1 arquiteto, 1 desenvolvedor e 1 testador.

\subsection{O SEnsES para Estudantes}

Diferentemente do SEnsES para professores, não é necessário ao estudante possuir cadastro na ferramenta. Para fazer uso das funcionalidades do sistema, basta que o estudante, utilizando um computador ou celular conectado à internet, acesse a página http://sensesoft.herokuapp.com/, digite o código PIN disponibilizado pelo seu professor e preencha os dados pessoais solicitados.

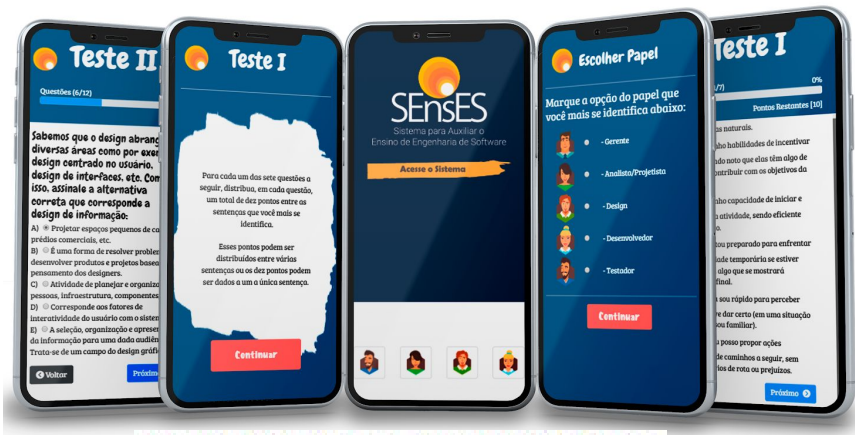

Figura 2: Senses para estudantes

Uma vez inserido o código PIN, o estudante será guiado de modo a iniciar a resolução do TRSPI. Uma vez concluído o teste, o algoritmo do sistema está 
desenvolvido de modo que, com base nas respostas do aluno, seja possível identificar e apresentar uma escala de aptidão para cada um dos papéis de uma equipe de projeto acadêmico de software.

\section{Avaliação da Ferramenta com Docentes}

Para a avaliação juntos aos docentes da foram utilizadas apresentações e entrevistas. Um total de três professores de Engenharia de Software participaram dessa avaliação, dos quais dois são mestre e um é especialista. Considera-se importante mencionar que nenhum dos professores entrevistados possui qualquer relação com o desenvolvimento da ferramenta.

As entrevistas realizadas com os docentes ocorreram de modo individual e cada uma delas teve duração aproximada de 1 hora. Os primeiros 15 minutos de cada entrevista foram utilizados de modo expositivo, consistindo apenas da apresentação, por parte do entrevistador, do que é a ferramenta, qual seu objetivo, como foi desenvolvida e quais as suas funcionalidades.

Após esse primeiro momento, os professores entrevistados foram convidados a fazer uso da ferramenta. O intuito dessa etapa da avaliação é possibilitar que os avaliadores possam analisar as funcionalidades e componentes disponíveis para a versão professor e para a versão aluno. Apesar desse momento avaliativo ser acompanhado pelo entrevistador, não houve intervenções enquanto os docentes realizavam essa etapa da avaliação.

Por fim, o tempo restante foi dedicado a coletar opiniões e percepções dos docentes sobre: o objetivo da ferramenta, o design proposto, a facilidade de uso e, principalmente, sobre a adequação desta ou não para aulas de Engenharia de Software. Uma síntese dos resultados coletados encontra-se na Tabela 1.

Tabela 1 : Respostas dos docentes entrevistados

\begin{tabular}{|c|c|c|c|}
\hline & Docente 1 & Docente 2 & Docente 3 \\
\hline $\begin{array}{l}\text { Objetivo da } \\
\text { Ferramenta }\end{array}$ & $\begin{array}{c}\text { "Claramente o } \\
\text { objetivo definido } \\
\text { (personalizar ensino) é } \\
\text { passível de ser } \\
\text { alcançado com o uso } \\
\text { da ferramenta". }\end{array}$ & $\begin{array}{l}\text { "A ferramenta atinge o } \\
\text { objetivo proposto". }\end{array}$ & $\begin{array}{l}\text { "Acredito ser possível } \\
\text { personalizar o ensino com o } \\
\text { uso da ferramenta". }\end{array}$ \\
\hline $\begin{array}{l}\text { Design } \\
\text { Desktop }\end{array}$ & "Bom". & "Muito bom". & $\begin{array}{l}\text { "Regular. Há pontos na } \\
\text { responsividade do sistema que } \\
\text { podem ser aperfeiçoados". }\end{array}$ \\
\hline Design Mobile & $\begin{array}{l}\text { "Bom, devido a } \\
\text { simplicidade". }\end{array}$ & "Muito bom". & "Bom". \\
\hline $\begin{array}{l}\text { Facilidade de } \\
\text { uso para o } \\
\text { professor }\end{array}$ & "Bom". & "Muito bom". & $\begin{array}{l}\text { "Bom, no entanto é necessário } \\
\text { considerar que a } \\
\text { responsividade precisa de } \\
\text { melhorias que podem tornar } \\
\text { ainda mais fácil o uso". }\end{array}$ \\
\hline
\end{tabular}




\begin{tabular}{|c|c|c|c|}
\hline $\begin{array}{l}\text { Adequação } \\
\text { em sala de } \\
\text { aula }\end{array}$ & $\begin{array}{l}\text { "Facilmente inserido } \\
\text { em sala de aula". }\end{array}$ & $\begin{array}{c}\text { "O uso em sala de aula é } \\
\text { simples". }\end{array}$ & "Adequado para uso". \\
\hline $\begin{array}{l}\text { Qualidade dos } \\
\text { relatórios } \\
\text { gerados }\end{array}$ & "Muito bom". & $\begin{array}{l}\text { "Fácil de entender, } \\
\text { objetivo e completo". }\end{array}$ & "Muito bom". \\
\hline $\begin{array}{l}\text { Avaliação } \\
\text { positiva } \\
\text { considerada } \\
\text { mais útil }\end{array}$ & $\begin{array}{c}\text { "Com certeza eu } \\
\text { utilizaria em sala de } \\
\text { aula". }\end{array}$ & $\begin{array}{l}\text { "A ferramenta possui uma } \\
\text { natureza inovadora e que } \\
\text { tem grande potencial de } \\
\text { ser muito bem vinda e } \\
\text { vista em sala de aula". }\end{array}$ & $\begin{array}{c}\text { "Acredito que a ferramenta é } \\
\text { de grande ajuda para os } \\
\text { professores e alunos." }\end{array}$ \\
\hline $\begin{array}{l}\text { Avaliação } \\
\text { negativa } \\
\text { considerada } \\
\text { mais útil }\end{array}$ & $\begin{array}{c}\text { "Algumas features } \\
\text { deveriam estar abertas } \\
\text { ao professor na versão } \\
\text { mobile." }\end{array}$ & $\begin{array}{c}\text { "Os relatórios gerados } \\
\text { poderiam ser } \\
\text { automaticamente enviados } \\
\text { para o email do } \\
\text { professor." }\end{array}$ & $\begin{array}{l}\text { "Verifiquei a versão mobile } \\
\text { para o aluno, acredito ser } \\
\text { necessário melhorias na } \\
\text { responsividade para diferentes } \\
\text { tamanhos de tela." }\end{array}$ \\
\hline
\end{tabular}

\section{Considerações Finais}

Conforme mencionado nas seções anteriores, este trabalho teve como objetivo apresentar uma ferramenta web, chamada SEnsES, capaz de auxiliar a personalização do ensino em disciplinas de Engenharia de Software (ES).

Apesar de algumas features ainda estarem em desenvolvimento, foi possível avaliar a ferramenta sob os seguintes aspectos: design, facilidade de uso e adequação ou não para uso em salas de aula de Engenharia de Software. Participaram da avaliação três professores de ES.

Como resultados da avaliação, foi possível obter indícios que o uso da ferramenta proporciona meios de: 1) alterar a dinâmica de ensino-aprendizagem de ES por meio da adoção de personalização de abordagens práticas focadas no aluno (e.g., personalização em equipes de projetos de software) e, 2) orientar professores na definição equipes de projeto acadêmico de software.

Como perspectivas de trabalhos futuros, encontram-se:

1) Finalizar o desenvolvimento da ferramenta

2) Realizar experimentos controlados em sala de aula, com docentes e discentes, a fim de verificar se os resultados obtidos reforçam ou refutam os resultados apresentados neste artigo.

\section{Referências}

[1] Cunha M. I., O bom professor e sua prática, 2 ed, São Paulo: Papirus, 182p., 2002.

[2] Kubo O. M., Botomé S. P., Ensino-Aprendizagem: Uma interação entre dois processos comportamentais, Revista Interação em Psicologia, vol 5, 2001.

[3] Portela, C.S., Vasconcelos A.M.S., Oliveira S.R.B., Um Modelo Interativo para o Ensino de Engenharia de Software Baseado em Abordagens Focadas no Aluno, VI Congresso Brasileiro de Informática na Educação (CBIE), 2017. 
[4] ACM/IEEE, Software Engineering 2014: Curriculum Guidelines for Undergraduate Degree Programs in Software Engineering, 2014.

[5] Souza M., França C., O Sucesso dos Jogos para Ensino de Disciplinas de Engenharia de Software sob a Ótica de uma Teoria Motivacional, V Congresso Brasileiro de Informática na Educação (CBIE), 2016.

[6] Belbin M. R., Team Roles at Work, Oxford: Butterworth Heinemann, 1993.

[7] Ferreira A. B., Moura A. R., Lima W. V., Uma Proposta de um Método para a Personalização do Ensino de Engenharia de Software, XXIII Conferência de Informática na Educação (TISE), 2018. 